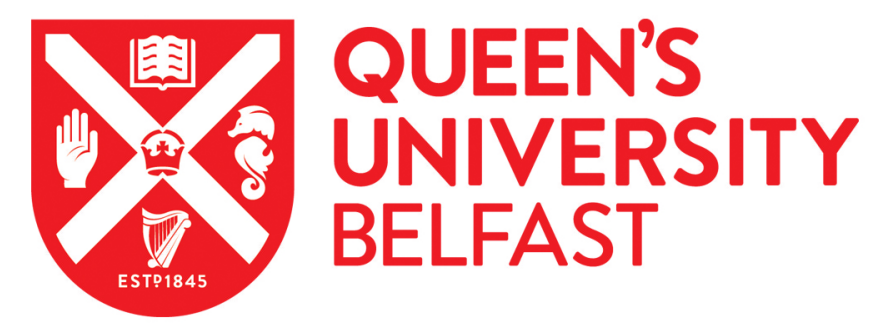

\title{
A UV-Vis Spectroscopic Method for Monitoring of Additive Particle Properties during Polymer Compounding
}

Whitaker, D. A., Buchanan, F., Billham, M., \& McAfee, M. (2018). A UV-Vis Spectroscopic Method for Monitoring of Additive Particle Properties during Polymer Compounding. Polymer Testing, 67.

https://doi.org/10.1016/j.polymertesting.2018.03.030

Published in:

Polymer Testing

Document Version:

Peer reviewed version

Queen's University Belfast - Research Portal:

Link to publication record in Queen's University Belfast Research Portal

\section{Publisher rights}

Copyright 2018 Elsevier.

This manuscript is distributed under a Creative Commons Attribution-NonCommercial-NoDerivs License

(https://creativecommons.org/licenses/by-nc-nd/4.0/), which permits distribution and reproduction for non-commercial purposes, provided the author and source are cited.

\section{General rights}

Copyright for the publications made accessible via the Queen's University Belfast Research Portal is retained by the author(s) and / or other copyright owners and it is a condition of accessing these publications that users recognise and abide by the legal requirements associated with these rights.

Take down policy

The Research Portal is Queen's institutional repository that provides access to Queen's research output. Every effort has been made to ensure that content in the Research Portal does not infringe any person's rights, or applicable UK laws. If you discover content in the Research Portal that you believe breaches copyright or violates any law, please contact openaccess@qub.ac.uk. 


\title{
A UV-Vis Spectroscopic Method for Monitoring of Additive Particle Properties during Polymer Compounding
}

\author{
Darren A. Whitaker ${ }^{a, 1}$, Fraser Buchanan ${ }^{b}$, Mark Billhamc, Marion McAfee ${ }^{a}$ \\ Ireland \\ a. Centre for Precision Engineering, Materials and Manufacturing, Institute of Technology Sligo, Sligo, \\ b. School of Mechanical and Aerospace Engineering, Queen's University, Belfast, United \\ Kingdom \\ c. Polymer Processing Research Centre, Queen's University, Belfast, United Kingdom
}

\section{Abstract}

Determination of the dispersion characteristics/or morphology of additives in polymer melts by fast, reliable and accurate on-line methods is highly desired in the polymer industry. An ultraviolet-visible (UV-Vis) spectroscopic methodology is described which meets these demands. It is demonstrated that the applied methodology may be developed on a cheap, packaging grade of Polylactic Acid (PLLA), an important bioresorbable polymer for the medical device industry, and still be accurate when implemented on a production line using a more expensive (medical) grade of the polymer compound. Simple chemometric algorithms are applied allowing the data processing step to be carried out in near real time, thus providing vital information to process operators which allows any out of control process to be identified and rectified without product loss.

Keywords: Biomaterials, Chemometrics, UV-Vis, Polymer, Polylactide, Compounding, Extrusion

\section{Introduction}

The addition of a particulate material to a polymer matrix is useful for many reasons. Additives can be incorporated to improve mechanical properties, barrier properties, aesthetics or just to reduce costs where the polymer is relatively expensive. For particulate additives within a polymer melt there are two main states; aggregated (or agglomerated) and suspended dispersion (Daming et al. 2003). Effective mixing is essential to ensure that the additive is well dispersed, ideally in a homogeneous fashion, to obtain improved performance of the polymer composite. Non-homogeneous dispersion may be encountered due to agglomeration and also when the forces acting on the melt cause breakdown of larger particles or when an inconsistent feed rate is seen. Ensuring effective dispersion of additives often means laboratory testing of samples after compounding which can be time consuming, in the meantime a batch of product may have been produced to unacceptable quality or long lead-times can ensue. In some cases re-compounding is necessary, resulting in extra time, energy and expense for the manufacturer. This becomes particularly problematic in the case of polymer compounds for the medical industry where quality demands are extremely high.

Medical devices, specifically implantable devices, made from bioresorbable polymeric materials offer a number of advantages over their traditional counterparts made from metallic materials including an ability to release drugs/bio-active agents at controlled rates(Tsuji et al. 2003). Additive materials in this case are commonly used to aid healing of the area where the

\footnotetext{
${ }^{1}$ Present address: PMTC, Bernal Institute, University of Limerick, Limerick, Ireland
} 
device is implanted(Agrawal and Athanasiou 1997) or tune degradation rates(Ara et al. 2002). The medical device industry demands that stringent quality control mechanisms are in place where high development costs can effect financial viability. This is especially the case where medical grades of polymers have material costs reaching into thousands of euros per kilogram, as such high development and waste costs can lead to production of a device being deemed unviable. On-line monitoring techniques have the capacity to overhaul the current, wasteful and expensive trial and error approach taken to the processing of bioresorbable polymers. Using these techniques, quality parameters may be fed back to the user at the earliest stage of development allowing processes to be optimised before material is wasted. This reduction in wastage leads to a reduction in energy, man hours and subsequently development costs.

\subsection{Monitoring of Particle Size in Compounding of Filled Polymer Systems}

On-line monitoring of the composition of polymer blends during extrusion has been investigated by both ultrasound measurements of polyethylene (PE) / polypropylene (PP) / polystyrene (PS) blends (Gendron et al. 1995) and Small angle light scattering of PE/PS blends ( $\mathrm{Li}$ et al. 1997) and PP / polyolefin elastomer (POE) blends (Alig et al. 2010). While the ultrasound measurements provided information on the \% loading only, small angle light scattering has shown potential for monitoring the morphology of the blend (size and shape of different domains in the melt). Monitoring of particulate additives in a polymer compound has also been carried out during extrusion. The volume fraction of calcium carbonate $\left(\mathrm{CaCO}_{3}\right)$ in PS was monitored on-line using dielectric measurements (Bur et al. 2002). Volume fraction of $\mathrm{CaCO}_{3}$ in $\mathrm{PP}$ and also volume fraction of PA6-glass fiber filled compounds have been studied by terahertz (THz) spectroscopy (Krumbholz et al. 2009). Content (w/w \%) of Magnesium Hydroxide in low density polyethylene (LDPE) was monitored during an extrusion process by near infrared (NIR) spectroscopy (Barnes and Sibley 2007). For the most part these studies used some form of multivariate data (MVDA) analysis in order to extract the relevant data from the measurements, the use of MVDA and chemometrics for extrusion monitoring is relatively widespread in the modern literature (Rohe et al. 1999; Alig et al. 2005; Becker and Eisenreich 2005; Vigh et al. 2014; Watari 2014).

A number of workers have also addressed the problem of determining the particle size of additives in a polymer compounding process, as a key measure of the degree of dispersion. Several studies have focussed particularly on the exfoliation of nanoclay (breakdown of microsized agglomerates of the clay into nano-thick platelets) during extrusion in a polymer matrix. Bur et al. (2005) and Bertolino and Canevarolo (2010) studied this via light intensity measurements, whereby, following Mie theory, exfoliated nano-particles scatter less light than agglomerated micro-particles and result in a higher intensity light signal being transmitted through the melt. UV-vis (Alig et al. 2010), fluorescence (Bur et al. 2007) and NIR-transmission spectroscopy (Witschnigg et al. 2010) have also been used to monitor dispersion of polymer/clay nanocomposites.

Monitoring of the morphology of micro-additives in a polymer compound during extrusion has been achieved by in-process ultrasound measurements. (Sun et al. 2005) reported the use of a neural network to relate degree of dispersion to ultrasonic velocity, attenuation, melt temperature and pressure measurements. Ultrasonic attenuation spectroscopy was applied to monitoring of particle size in compounding of $\mathrm{CaCO}_{3}$ with PP (Alig et al. 2010). This work differed from the previous study in that here use was made of the fact that the ultrasonic attenuation at different frequencies is dependent on particle size. Alig et al. (2010) argue this is more directly related to particle size than integral attenuation or velocity measurements and hence required less data and less complex chemometric modelling for calibration of the measurements to particle size. 


\subsection{Model System}

The chosen polymer material for this study, Polylactic acid, is a type of polyester which belongs to a group of materials known as bioresorbable polymers which are slowly becoming more prevalent in the medical device industry.

The additive material chosen for the present study represents a type which has been used extensively with PLA. This was chosen to ensure that the composites represented a relevant material within the medical field. Beta-Tricalcium phosphate $\left(\mathrm{Ca}_{3}\left(\mathrm{PO}_{4}\right)_{2}\right)$ or $\beta$-TCP, a biodegradable, bioactive ceramic material commonly used in orthopaedic devices, has been investigated in composites of: PLGA (Ehrenfried et al. 2008), PLLA (Ignatius et al. 2001) and PDLLA (Lin et al. 1999). Particle dispersion has been identified in the mentioned studies as a parameter which effects final properties of a product, therefore a robust tool to measure this during processing would be greatly advantageous. Additionally dimensions of medical devices can be in the micro-scale (tubes, membranes, tissue scaffolds etc.), as such it is important that agglomerations of filler particles are kept small relative to the product dimensions. In this work we are focussing on monitoring of the size of particulate agglomerates (represented by fixed particle size additives), and ensuring that they do not exceed a specific size where they become significant relative to the product dimensions and hence could potentially result in aesthetic or mechanical defects. Traditional monitoring regimes focus on monitoring fluctuations in percentage loading, however with controlled pre-mixing or if using modern controlled feeding technology, controlling percentage loading is much less of an issue. Monitoring of PLA based polymers by spectroscopic methods reported in the literature focusses on material degradation (Wang et al. 2008), this demonstrates the adaptability of the UV-Vis measurement system and suggests that future work may be able to combine filler and degradation monitoring using a single technique.

In this manuscript we aim to demonstrate an on-line measurement technique which is capable of determining in real time if particle (and by extension agglomerate) sizes are within a specified range and are not forming large agglomerates or are breaking down into smaller particulates. The technique has the further advantage of $100 \%$ sampling and validating of the filler dispersion in a non-invasive manner.

As defined agglomeration is difficult to control, the methodology was tested using a model system of defined particle sizes of $\beta$-TCP. The additive with a small mean particle size represents well dispersed, and large mean particle size represents fully agglomerated additives. These were tested individually, and then in a mixture of sizes to closer represent a real compounding process whereby small numbers of large agglomerates may be present among a majority of well-dispersed particles. Additionally we report the successful use of multivariate calibration models (using linear discriminate analysis (LDA) and partial least squares (PLS) regression), developed on a cheap packaging grade material for prediction of the same properties in a more expensive medical grade material without the need for a corrective transfer methodology. These two materials exhibit different optical properties (i.e. colour) which can be problematic for spectroscopies which rely on light transmission. This difference means that a calibration model built for one material may not be directly applicable to the other.

\subsection{Multivariate Analysis}

A single spectrum usually contains a large number of variables; two approaches are possible to utilise spectral information for calibration of quantitative models, univariate or multivariate methodologies. In univariate analysis, covariation with other variables is explicitly neglected and this may lead to important features being ignored (Bro and Smilde 2014). For this reason within the analytical chemistry field it is standard practice to carry out multivariate analysis on spectroscopy data (Bro 2003). In general multivariate models are more adequate than univariate 
models - however, it is always possible to discard variables, with a mathematical justification, such that a univariate approach is re-obtained.

Multivariate data analysis (MVDA) describes the practice of using mathematical and statistical tools to extract information from data tables where each observation contains a large number of variables. In such cases, the desired information lies in the correlation structure between variables, this often leads to erroneous results when tested independently. MVDA by means of projection methods is able to analyse data where challenges such as multidimensionality of the data set, multicollinearity, missing data and variation introduced by deviating factors such as experimental error and noise occur. Principal Component Analysis (PCA) is a commonly used projection method in MVDA, this projects data onto a lower dimensional space where is can be easily inspected. Linear Discriminant Analysis (LDA) is a commonly used technique to classify data into discrete sets i.e. yes/no, working/broken or running/faulty. Regression modelling such as partial least squares (PLS) regression is another type of MVDA where the aim is prediction of a response (quantity) rather than classification (Eriksson et al. 2013)

\subsubsection{Transferability of Multivariate Models}

Multivariate calibration models are utilised in combination with these spectroscopic techniques, allowing only relevant data to be used to inform the predictive models. This causes problems when transferring a model between instruments, material grades or even when using the same instrument under different environmental conditions (temperature, relative humidity etc.). Various methods of calibration transfer exist and are summarised in a review by (Feudale et al. 2002).

\section{Experimental}

\subsection{Materials}

Two grades of PLLA were used: Ingeo 4043D (Natureworks LLC, NE, USA) which is a general purpose extrusion packaging grade with D isomer content of $4.2 \%$; secondly Purasorb 9620 (Corbion Purac, Gorinchem, Netherlands), a medical grade grade material with $4 \% \mathrm{D}$ isomer content and a maximum of $0.1 \mathrm{wt} \%$ residual monomer.

Whitlockite $\beta$-TCP powders (Plasma Biotal, Derbyshire, UK) with the following specifications were used as additives; P228S (mean particle size (D50) - $4.99 \mu \mathrm{m}$ ) and P322S SD (mean particle size $(\mathrm{D} 50)-31.4 \mu \mathrm{m})$, referred to from herein nominally as 5 , and $30 \mu \mathrm{m}$ for simplicity.

\subsection{Extrusion}

The $\beta$-TCP powder was dried at $80{ }^{\circ} \mathrm{C}$ before being accurately weighed then tumble mixed with the PLLA. All PLLA/ $\beta$-TCP powder mixes were then dried in a desiccant drier at $70{ }^{\circ} \mathrm{C}$ overnight prior to extrusion. Dispersion trials were carried out using a Haake $16 \mathrm{~mm}$ twin-screw extruder with a $1 \mathrm{~mm}$ slit die attached. The extrudate was then fed through a Dr Collins 3-roll stack to produce a strip of fixed width and thickness approximately $25 \mathrm{~mm}$ x $0.5 \mathrm{~mm}$. Pre-mixed dry blends of PLLA 4043D with $20 \% \mathrm{w} / \mathrm{w}$ of $\beta$-TCP powder or PLLA Purasorb 9620 and $20 \%$ $\mathrm{w} / \mathrm{w} \beta$-TCP powder were used direct from the desiccant drier at $70 \mathrm{flC}$. The extruder was set at barrel temperatures of $190{ }^{\circ} \mathrm{C}: 195{ }^{\circ} \mathrm{C}: 200{ }^{\circ} \mathrm{C}: 200{ }^{\circ} \mathrm{C}: 200{ }^{\circ} \mathrm{C}$ and adapter and die temperatures of $200{ }^{\circ} \mathrm{C}$. 
To ensure residence times and mixing remained constant the extruder was run at $300 \mathrm{rpm}$ and feed rate of $15 \%$ of maximum, the extruder was started up with the virgin PLLA material followed by the pre-mixed compounds. During extrusion, barrel temperature, pressure, torque, screw speed and feed rate were monitored and recorded by the Haake Polysoft operating system. On exiting the die the material was chilled on a 3-roll stack initially set to $60 \mathrm{flC}$ and at a line speed of $1.6 \mathrm{~m} / \mathrm{min}$, the temperature, speed and roll gap were adjusted to achieve a consistent thickness of product, (the regularity of this was influenced by the consistency of the powder feed from the metering screws).

In addition to single particle size composites, samples were prepared containing a mixture of 5 and $30 \mu \mathrm{m}$ particle sizes, here the total additive concentration was kept at $20 \% \mathrm{w} / \mathrm{w}$ and the ratio of $5: 30 \mu \mathrm{m}$ was varied. This approach was used to create a bimodal size distribution to more closely mimic what would likely be seen in a particle agglomeration scenario. Ratios of 19:1, 18:2 and 15:5\% w/w were used. The $\beta$-TCP powder was dried at $80 \mathrm{flC}$ before being accurately weighed then tumble mixed with the Natureworks 4034D PLLA. Extrusion was carried out as above.

\subsection{Microscopy}

To confirm the loading and particle size post extrusion films of the extrudate were prepared and evaluated using a Nikon Eclipse ME600 compound microscope running the NIS-Elements AR 3.2 software package.

\subsection{UV-Vis Spectroscopy}

UV-Vis spectra were recorded at $10 \mathrm{~s}$ intervals through the melt using a FOSAS (FOSMesstechnik, Germany) fibre optic spectral acquisition system consisting of a broadband halogen light source and a usb spectrometer unit. The fibre optic probes were mounted into the slit die channel located directly after the extruder barrel (figure 1). UV-Vis spectra in the wavelength range $290-980 \mathrm{~nm}$ were recorded through the melt with an optical path length of $1 \mathrm{~mm}$.

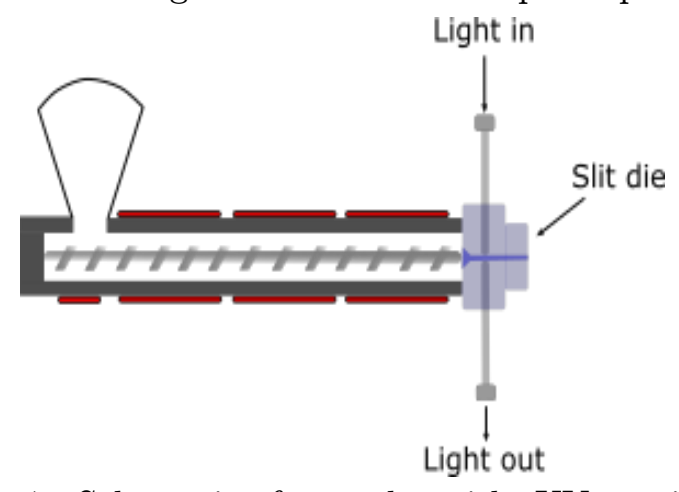

Figure 1: Schematic of extruder with UV-monitoring

\subsection{Data Analysis}

Multivariate analyses were carried out using the $\mathrm{R}$ statistical language (RDevelopmentCoreTeam 2013) and RStudio as a graphical front-end (RStudioTeam 2015). Principal component analysis (PCA) was carried out using the prcomp routine in the base $\mathrm{R}$ package. Linear discriminant analysis (LDA) was carried out using the lda routine in the MASS package for R (Venables and Ripley 2002). Partial Least Square (PLS) analysis was carried out using the plsr routine in the PLS package (Mevik et al. 2015). Data files were batch imported using custom written import routines for the hyperspec package for $\mathrm{R}$ (Beleites and Sergo 2015). 
As the filler size is a physical effect it can be observed on the full wavelength range of the recorded spectra, therefore no trimming of spectra is carried out. Additionally, standard spectral pre-processing methodologies aim to remove the scattering effects which can interfere with chemical information in the spectrum (Rinnan et al. 2009) and as such they are not appropriate therefore the raw absorbance data is used to train the calibration models.

To ensure the robustness of the model, extrusion runs were carried out on separate days using the Natureworks grade of PLA. Data from the first run was used to calibrate an LDA model where groupings of "good" and "bad" were given to the 5 and $30 \mu \mathrm{m}$ particle sizes respectively, and also to calibrate a PLS model where 5 and $30 \mu \mathrm{m}$ were used as absolute predictor values. Data from a second and third run was used as a validation set, this is presented as a time series.

Additionally the predictive model was applied to a new set of data containing spectra from the Purasorb grade of PLA, again with the aim of correctly classifying and/or quantifying the particle size present.

\section{Results and Discussion}

\subsection{Monitoring of Different Particle Size Additives during Extrusion}

The $\beta$-TCP particle size had a noticeable influence on the UV-Vis spectra (Figure 2). Larger particle sizes result in a greater amount of light reaching the detector and thus a larger peak. While, within this particle size range, larger particles scatter more light; they also have greater particle to particle spacing and have a smaller population at the same weight percent as the small particles (Wriedt 2012). This results in a greater transparency of the material and thus greater signal intensity with increasing particle size. The particle size and loading post extrusion was confirmed, using microscopy, to be that expected from the experimental inputs.

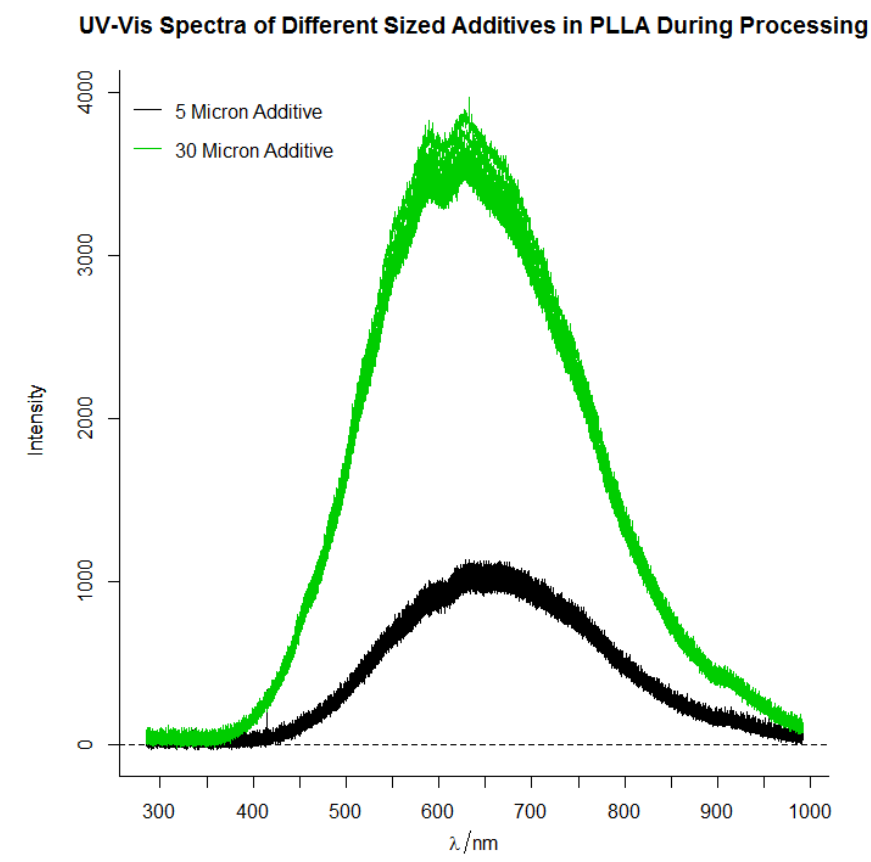

Figure 2 - UV-Vis spectra of $20 \% \mathrm{w} / \mathrm{w}$ loading of 5 (green), 30 (black) $\mu \mathrm{m}$ particle size TCP in PLLA matrix 
While the separation in the spectra for the two particle sizes is obvious when viewing the data as a whole, detecting a sudden change in particle size in real time is not quite so obvious from the raw spectral data. This means that in time series' data changes become difficult to monitor and as such reduction and presentation of useful variables is advantageous. PCA allows the variation in the multivariate spectrum to be displayed in a more useful manner (Figure 3). It can be seen that when the extruder feed is switched from one particle size to another the change is seen quite obviously on the 1st Principal Component (PC1) time series graph. Additionally, on in the left hand panel the feed was stopped and the extruder allowed to empty prior to the second feed starting whereas in the right hand panel the feeds were swapped without allowing the extruder to empty, creating an overlap of feed material.

\section{Principal Component Scores from two runs}
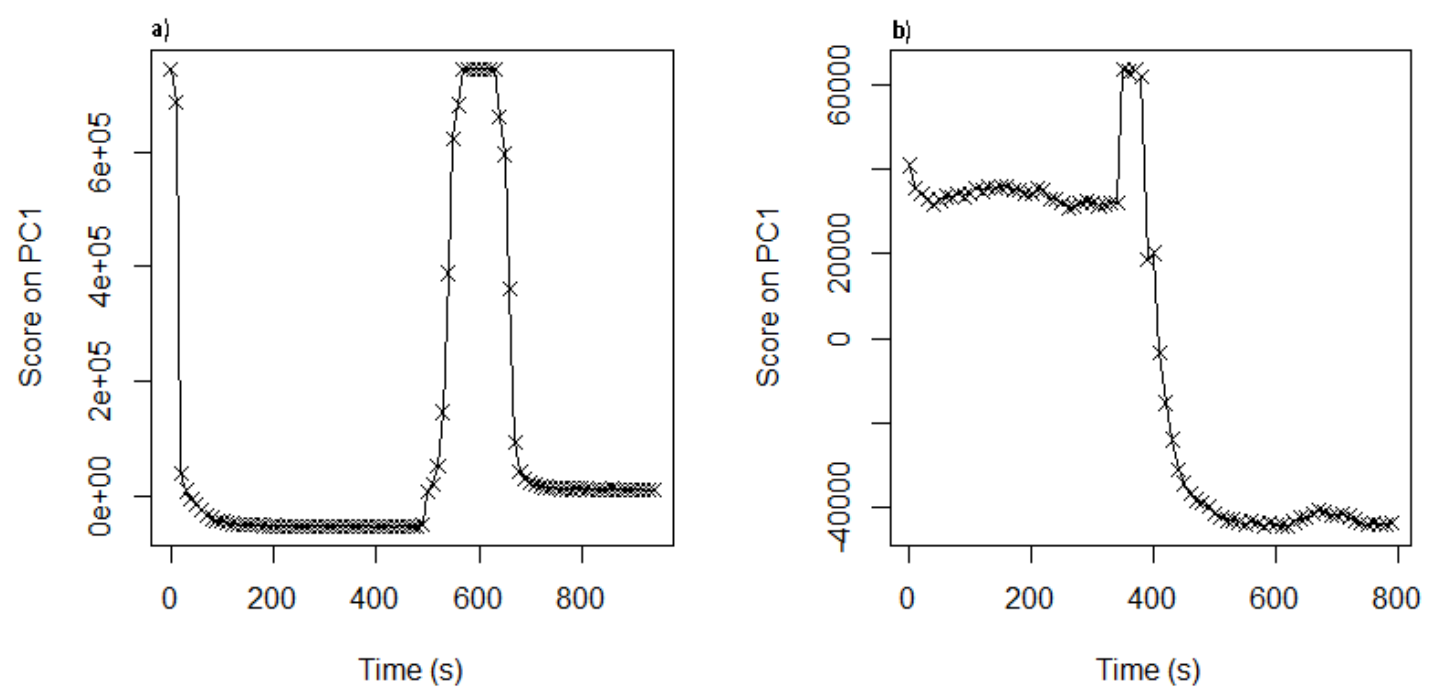

Figure 3 - PC1 score of each UV-Vis spectrum during the extrusion run

PCA allows the trend to be observed, however there is no qualitative information present. To enable the display of such information an LDA model was trained on the initial data and applied to the same runs as the PCA model above. It can now be deduced (Figure 4) when the particle size is classified as "good" or "bad." This output is much more useful for an operator to be faced with. 


\section{Linear Discriminate Scores from two runs}

a)

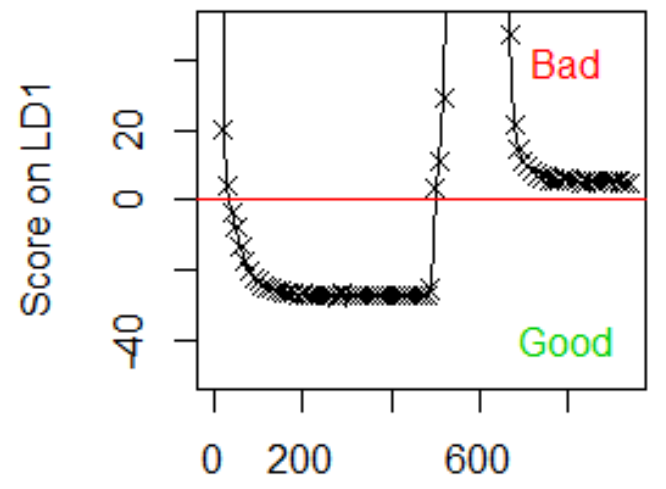

Time (s) b)

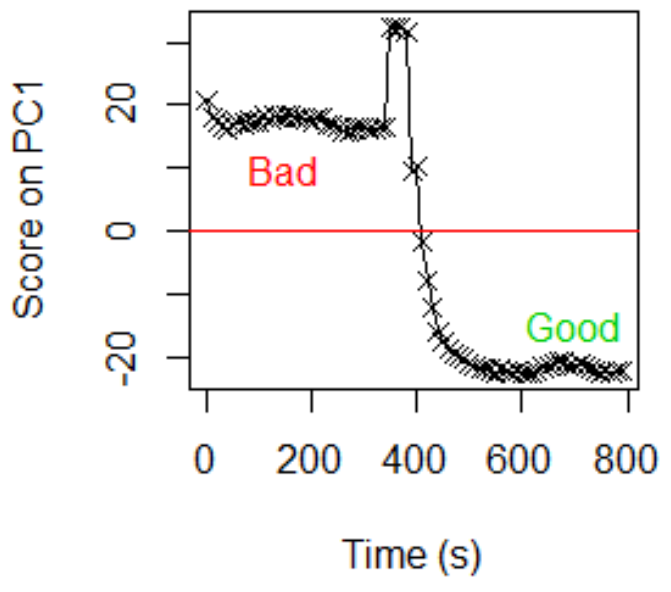

Figure 4 - LDA showing class membership of spectra recorded as a function of time

Finally a PLS model is trained upon the same datasets. This allows a quantitative prediction on the D50 to be displayed (Figure 5). The predictive accuracy is reasonable with steady state means being: $31.4 \pm 0.64 \mu \mathrm{m}$ and $30.40 \pm 0.20 \mu \mathrm{m}$ for the $30 \mu \mathrm{m}$ particles and $13.09 \pm 0.16 \mu \mathrm{m}$ and $7.62 \pm 0.51 \mu \mathrm{m}$ for the $5 \mu \mathrm{m}$ particles.

\section{Predicted D50 from two runs}

a)

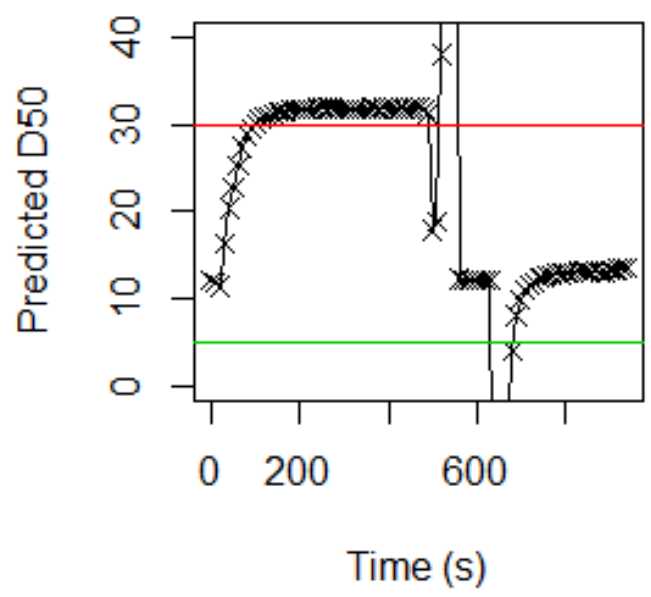

b)

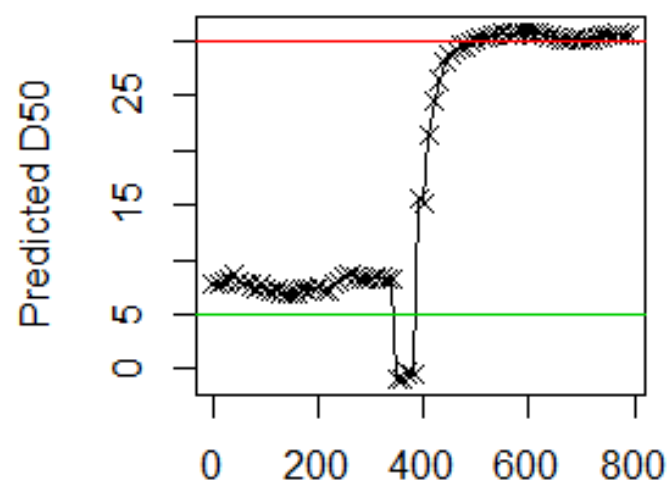

Time (s)

Figure 5 - PLS predictions of D50. Data shows a continuous time series where the feed was changed at ca. 500 seconds from $30 \mu \mathrm{m} \beta$-TCP pre-mixed with PLLA to $5 \mu \mathrm{m} \beta$-TCP premixed with PLLA 


\subsubsection{Testing model with Purac Purasorb 9620 (Medical Grade Polymer)}

Transferability of multivariate modelling techniques is a complicated matter and multiple corrective methods exist (Feudale et al. 2002). The best scenario however is when a corrective method need not be applied. In the case of the two PLLA grades used in this work the former is true. The predictive models developed using the Natureworks PLLA were tested using a set of melt data recorded during processing of Purac Purasorb 9620 PLLA under the same temperature conditions using a $20 \% \mathrm{w} / \mathrm{w}$ additive content.

The medical grade PLLA was compounded with the $30 \mu \mathrm{m} \beta$-TCP which was then switched to the $5 \mu \mathrm{m}$ feed mid processing. The previously trained PCA, LDA and PLS models were applied to the spectral data, this allows the trend in a continuous time series to be evaluated. Additionally qualitative (LDA) and quantitative information (PLS) can be gained (Figure 6). Model performance was varied, the LDA was able to correctly classify all the spectra into " good" or " bad" and the PLS was able to predict the size of the $30 \mu \mathrm{m}$ particles as 29.13ffi0.64 $\mu \mathrm{m}$. However, the $5 \mu \mathrm{m}$ particles however showed had larger variation of prediction (3.14ffi2.04 $\mu \mathrm{m})$. The process, however, did not reach steady state in the allotted time interval and so the variation is to be expected. Pressure fluctuations due to unsteady throughput was observed upon switchover. This would be expected to cause some uncertainty in the determination of the particle size, however the predictions are still reasonably accurate even with processing issues indicating that the model is robust.

This result is of relevant interest to industries who do not wish to use the more expensive grades of material to calibrate measurement systems, this is an advantage of the UV-Vis system.

PCA, LDA and PLS Predictions from Purasorb Material
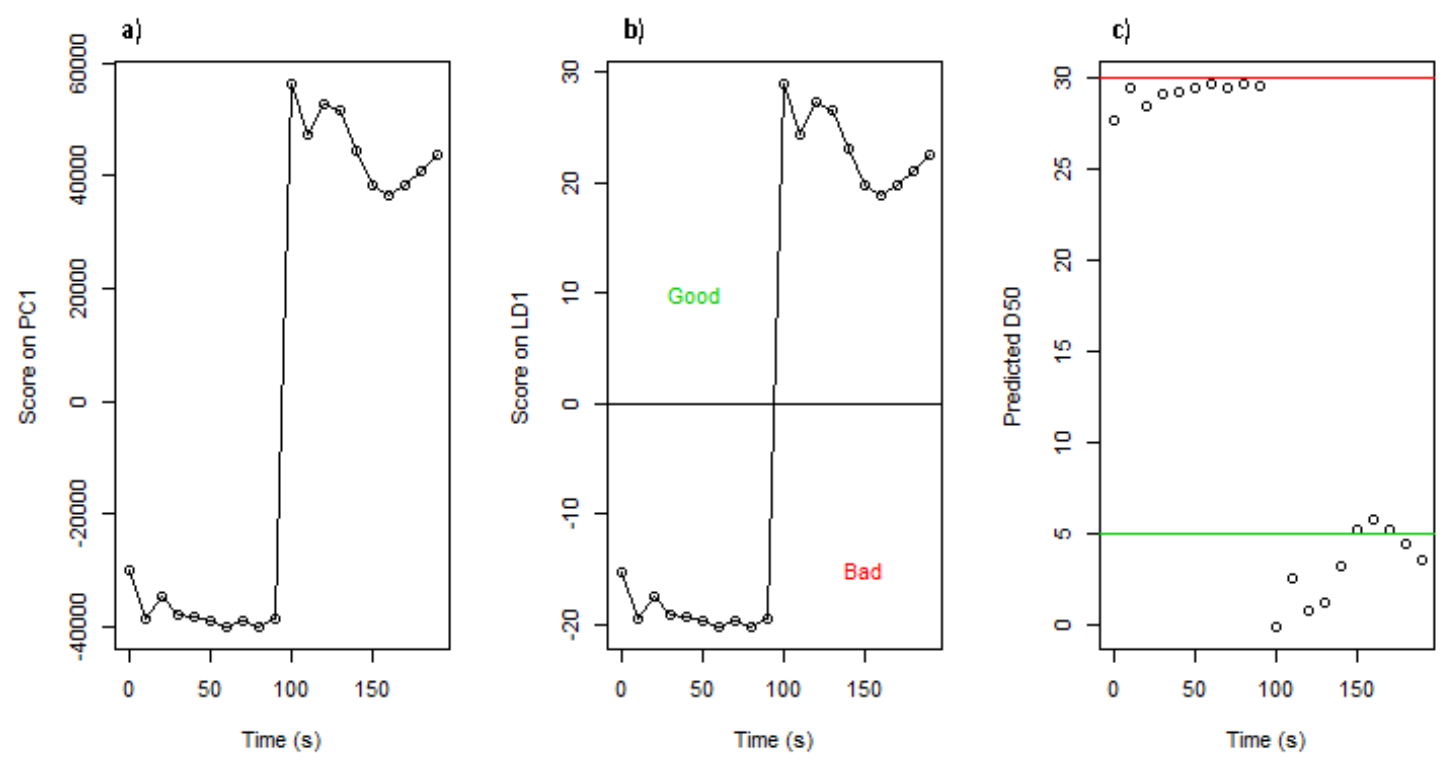

Figure 6 - Evaluation of Purasorb Melt Spectra using PCA, LDA and PLS Models. Data shows a continuous time series where the feed was changed at $c a .100$ seconds from $30 \mu \mathrm{m} \beta$ -

TCP pre-mixed with PLLA to $5 \mu \mathrm{m} \beta$-TCP premixed with PLLA

\subsection{Monitoring of Mixed Particle Size Additives during Extrusion}

In order to more closely represent a process where agglomeration of filler particles is taking place, different particle sizes of $\beta$-TCP were mixed in different ratios. The aim of the monitoring in this case was to detect when the $\mathrm{w} / \mathrm{w}$ of large particle in the extrudate goes above an upper 
limit. A set of 10 spectra were recorded for each variant of loading during extrusion, this was used to train the models. The models were then tested on a time series set of data where the feed was changed during extrusion. There is not a large observable difference in the spectra of the different loadings, and in fact some overlap can be seen (Figure 7), this is owing to the similarity of the mixtures.

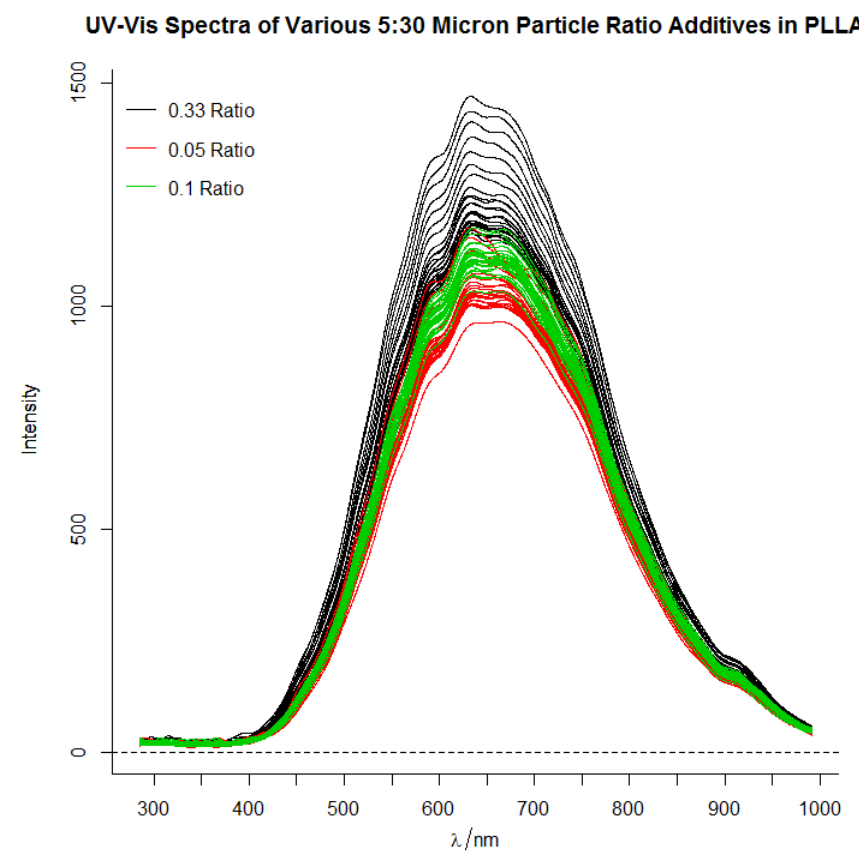

Figure 7 - UV-Vis spectra through the melt of PLLA containing different ratios of $5 \mu \mathrm{m}: 15$ $\mu \mathrm{m} \beta$-TCP premixed with PLLA

As in the previous section three separate models were built on the calibration data set and these were used to interrogate the validation data (Figure 8). PCA being the simplest model allows visualisation of the variance but offers little more information, LDA and PLS were again employed to glean additional information. LDA model accuracy was very high where all but two samples were assigned to the correct class, in this case "bad" represented the $15: 5 \mathrm{w} / \mathrm{w}$ ratio and "good" represented the remaining two ratios. PLS accuracy was calculated from the average across the time points of the various materials being processed (Figure 8c), this showed a maximum of $0.02 \%$ deviation from expected values (Table 1). This represents a good performance showing that the multivariate methodology allows the predictions to be robust even when the process is not at a full steady state. 

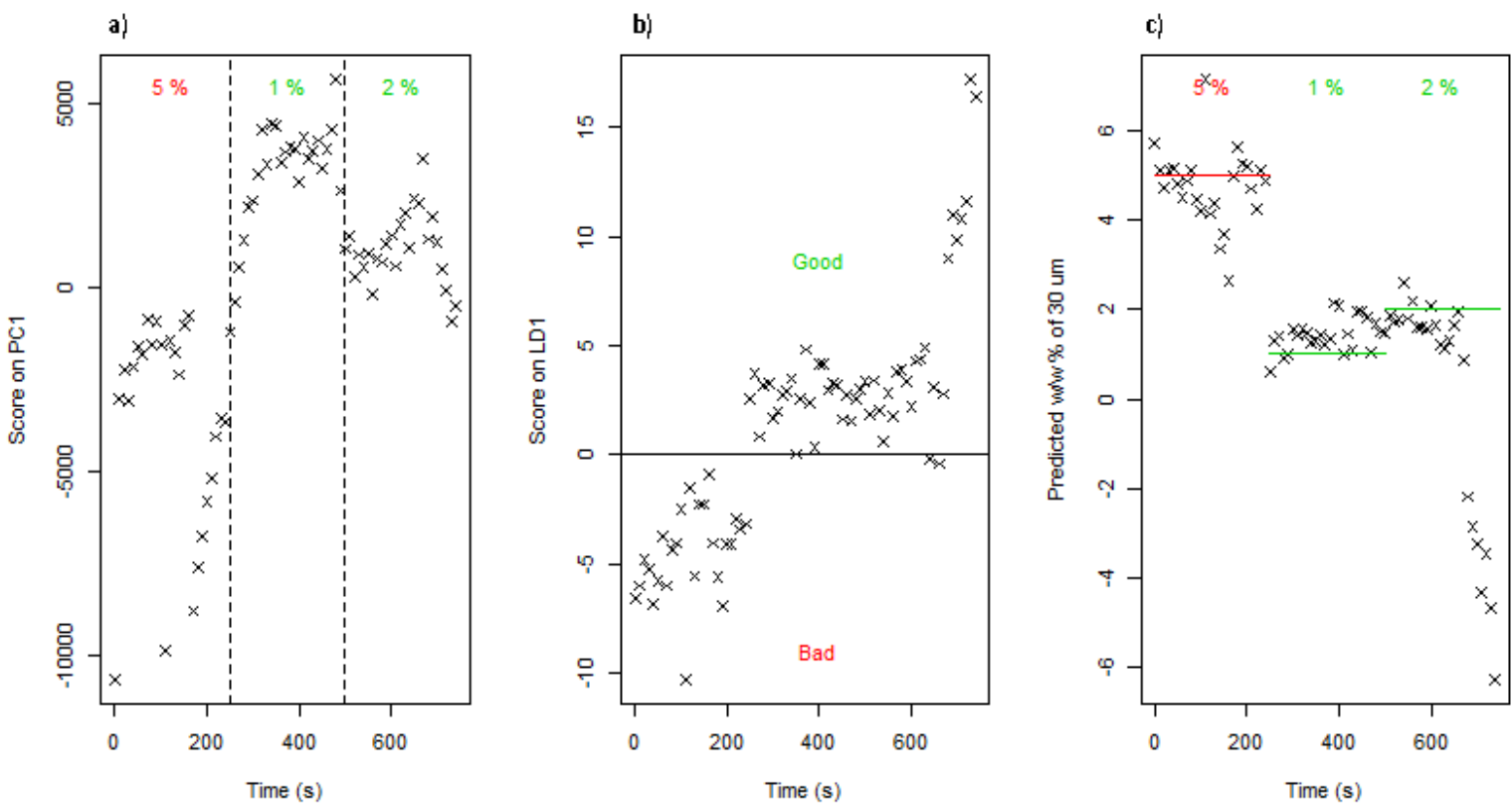

Figure 8 - Evaluation of Melt Spectra using PCA, LDA and PLS Models. Data shows a continuous time series where the feed was changed at ca. 250 and 500 seconds to a different ratio of $5 \mu \mathrm{m}: 15 \mu \mathrm{m} \beta$-TCP premixed with PLLA

Table 1 - PLS Predictive Accuracy

\begin{tabular}{ll}
\hline Actual $30: 5$ ratio & Predicted Ratio \\
\hline 0.33 & 0.31 \\
0.05 & 0.07 \\
0.1 & 0.10 \\
\hline
\end{tabular}

Online measurement of mixed size microadditives during melt processing using ultrasonic spectroscopy was reported by (Alig et al. 2005), this work used a PLS methodology to predict the content of $85 \mu \mathrm{m}$ particles in a $5 \mu \mathrm{m}: 85 \mu \mathrm{m}$ mixed system, while this was successful the presently reported method shows a greater sensitivity, while maintaining a good predictive accuracy.

The three models here are computationally simple and can give results in real time. Previously Alig et al. (2010) showed a correlation between NIR spectra and particle morphology under different processing parameters. This focussed on nano-additives, was mathematically heavy and required calculation of the scattering cross-sections of the particles. The methodologies used here require little background information or extensive mathematical knowledge.

The results suggest that with careful calibration of the models; differences in particle size, loading and loading composition can be distinguished in almost real time. These models can be developed relatively simply and cheaply (not much data required, cheap material can be used for model development). Variations in particle size (which can be indicative of agglomerates or particle breakdown) can be identified in real time with $100 \%$ sampling - compared to lab imaging on limited samples. Further the results indicate that the method is robust even with fluctuations in the process. This allows the user to make informed process decisions in real time. 


\section{Conclusion}

UV-Vis spectroscopy coupled with multivariate analysis has been shown to be effective at classifying particles of different sizes (which can be viewed as models of differing filler particle agglomeration) within a molten polymer matrix. Additionally PLS modelling was able to predict D50 or particle size ratio with reasonable accuracy. The transferability of the predictive models from an extrusion grade to a medical grade of PLLA is highly significant due to the high costs of collecting calibration data and utilising trial and error processing approaches when using the expensive medical grade materials. Future work will further optimise the models by the inclusion of more data points in the calibration set, and additionally a similar approach may be carried out on another polymer-additive system where agglomeration can be directly observed.

\section{References}

Agrawal, C.M., Athanasiou, K.A. (1997) 'Technique to control pH in vicinity of biodegrading PLA-PGA implants', Journal of Biomedical Materials Research, 38(2), 105-114.

Alig, I., Fischer, D., Lellinger, D., Steinhoff, B. (2005) 'Combination of NIR, Raman, ultrasonic and dielectric spectroscopy for in-line monitoring of the extrusion process', Macromolecular Symposia, 230, 5158.

Alig, I., Steinhoff, B., Lellinger, D. (2010) 'Monitoring of polymer melt processing', Measurement Science and Technology, 21(6), 62001.

Ara, M., Watanabe, M., Imai, Y. (2002) 'Effect of blending calcium compounds on hydrolytic degradation of poly(DL-lactic acid-co-glycolic acid)', Biomaterials, 23(12), 2479-2483.

Barnes, S., Sibley, M. (2007) 'Process monitoring of polymer melts using in-line spectroscopy', Transactions of the ..., 5, 453-465, available: http://tim.sagepub.com/content/29/5/453.short.

Becker, W., Eisenreich, N. (2005) 'Measurement of the Irganox content in polypropylene polymers during extrusion', Journal of Near Infrared Spectroscopy, 13(3), 147-154.

Beleites, C., Sergo, V. (2015) 'hyperSpec: a package to handle hyperspectral data sets in R', available: http://hyperspec.r-forge.r-project.org.

Bertolino, M.K., Canevarolo, S. V. (2010) 'Preparation of extruded melt-mixed polypropylene/montmorillonite nanocomposites with inline monitoring', Polymer Engineering \& Science, 50(3), 440-445, available: http://doi.wiley.com/10.1002/pen.20921.

Bro, R. (2003) 'Multivariate calibration: What is in chemometrics for the analytical chemist?', Analytica Chimica Acta, 500(1-2), 185-194.

Bro, R., Smilde, A.K. (2014) 'Principal component analysis', Analytical Methods, 6(9), 2812, available: http://xlink.rsc.org/?DOI=c3ay41907j.

Bur, A.J., Lee, Y.H., Roth, S.C., Start, P.R. (2005) 'Measuring the extent of exfoliation in polymer/clay nanocomposites using real-time process monitoring methods', Polymer, 46(24), 10908-10918.

Bur, A.J., Roth, S.C., McBrearty, M. (2002) 'In-line dielectric monitoring during extrusion of filled polymers', Review of Scientific Instruments, 73(5), 2097.

Bur, A.J., Roth, S.C., Start, P.R., Lee, Y.H., Maupin, P.H. (2007) 'Monitoring Clay Exfoliation During Polymer/Clay Compounding Using Fluorescence Spectroscopy', Transactions of the Institute of Measurement and Control, 29(5), 403-416.

Daming, W., Qingyun, M., Ying, L., Yumei, D., Weihong, C., Hong, X., Dongyun, R. (2003) 'In situ bubblestretching dispersion mechanism for additives in polymers', Journal of Polymer Science Part B: Polymer Physics, 41(10), 1051-1058, available: http://doi.wiley.com/10.1002/polb.10450.

Ehrenfried, L.M., Patel, M.H., Cameron, R.E. (2008) 'The effect of tri-calcium phosphate (TCP) addition on the degradation of polylactide-co-glycolide (PLGA)', Journal of Materials Science: Materials in Medicine, 19(1), 459-466.

Eriksson, L., Byrne, T., Johansson, E., Trygg, J., Vikstrom, C. (2013) Multi- and Megavariate Data Analysis Basic Principles and Applications, Third. ed, MKS Umetrics AB.

Feudale, R.N., Woody, N.A., Tan, H., Myles, A.J., Brown, S.D., Ferre, J. (2002) 'Transfer of multivariate 
calibration models: A review', Chemometrics and Intelligent Laboratory Systems, 64(2), 181-192.

Gendron, R., Tatibouët, J., Guèvremont, J., Dumoulin, M.M., Piché, L. (1995) 'Ultrasonic behavior of polymer blends', Polymer Engineering \& Science, 35(1), 79-91, available: http://dx.doi.org/10.1002/pen.760350111.

Ignatius, A.A., Wolf, S., Augat, P., Claes, L.E. (2001) 'Composites made of rapidly resorbable ceramics and poly ( lactide ) show adequate mechanical properties for use as bone substitute materials', Journal of biomedical materials research. Part A, 57(1), 126-131.

Krumbholz, N., Hochrein, T., Vieweg, N., Hasek, T., Kretschmer, K., Bastian, M., Mikulics, M., Koch, M. (2009) 'Monitoring polymeric compounding processes inline with $\mathrm{THz}$ time-domain spectroscopy', Polymer Testing, 28(1), 30-35, available: http://dx.doi.org/10.1016/j.polymertesting.2008.09.009.

Li, S., Migler, K.B., Hobbie, E.K., Kramer, H., Han, C.C., Amis, E.J. (1997) 'Light-Scattering Photometer with Optical Microscope for the In-Line Study of Polymer Extrusion', Polymer, 2935-2943.

Lin, F.-H., Chen, T., Lin, C., Lee, C. (1999) 'The Merit of Sintered PDLLA/TCP Composites in Management of Bone Fracture Internal Fixation', Artificial Organs, 23(2), 186-194, available: http://doi.wiley.com/10.1046/j.1525-1594.1999.06164.x.

Mevik, B.-H., Wehrens, R., Liland, K.H. (2015) 'pls: Partial Least Squares and Principal Component Regression', available: https://cran.r-project.org/package=pls.

RDevelopmentCoreTeam (2013) 'R: A Language and Environment for Statistical Computing', available: http://www.r-project.org.

Rinnan, A.., Berg, F. van den, Engelsen, S.B. (2009) 'Review of the most common pre-processing techniques for near-infrared spectra', TrAC - Trends in Analytical Chemistry, 28(10), 1201-1222.

Rohe, T., Becker, W., Kölle, S., Eisenreich, N., Eyerer, P. (1999) 'Near infrared (NIR) spectroscopy for inline monitoring of polymer extrusion processes', Talanta, 50(2), 283-290.

RStudioTeam (2015) 'RStudio: Integrated Development Environment for $R^{\prime}$, available: http://www.rstudio.com/.

Sun, Z., Jen, C.K., Yan, J., Chen, M.Y. (2005) 'Application of ultrasound and neural networks in the determination of filler dispersion during polymer extrusion processes', Polymer Engineering and Science, 45(6), 764-772.

Tsuji, T., Tamai, H., Igaki, K., Kyo, E., Kosuga, K., Hata, T., Nakamura, T., Fujita, S., Takeda, S., Motohara, S., Uehata, H. (2003) 'Biodegradable stents as a platform to drug loading.', International journal of cardiovascular interventions, 5(1), 13-16.

Venables, W.N., Ripley, B.D. (2002) Modern Applied Statistics with S [online], Statistics and Computing, Springer New York: New York, NY, available: http://link.springer.com/10.1007/978-0-387-21706-2.

Vigh, T., Drávavölgyi, G., Sóti, P.L., Pataki, H., Igricz, T., Wagner, I., Vajna, B., Madarász, J., Marosi, G., Nagy, Z.K. (2014) 'Predicting final product properties of melt extruded solid dispersions from process parameters using Raman spectrometry', Journal of Pharmaceutical and Biomedical Analysis, 98, 166-177.

Wang, Y., Steinhoff, B., Brinkmann, C., Alig, I. (2008) 'In-line monitoring of the thermal degradation of poly(l-lactic acid) during melt extrusion by UV-vis spectroscopy', Polymer, 49(5), 1257-1265, available: http://linkinghub.elsevier.com/retrieve/pii/S0032386108000451 [accessed 13 Jan 2014].

Watari, M. (2014) 'A review of online real-time process analyses of melt-state polymer using the nearinfrared spectroscopy and chemometrics', Applied Spectroscopy Reviews.

Witschnigg, A., Laske, S., Kracalik, M., Feuchter, M., Pinter, G., Maier, G., Märzinger, W., Haberkorn, M., Langecker, G.R., Holzer, C. (2010) 'In-line characterization of polypropylene nanocomposites using FT-NIR', Journal of Applied Polymer Science, 21(7), n/a-n/a, available: http://doi.wiley.com/10.1002/app.32024.

Wriedt, T. (2012) The Mie Theory [online], Springer Series in Optical Sciences, Springer Berlin Heidelberg: Berlin, Heidelberg, available: http://dx.doi.org/10.1007/978-3-642-28738-1. 


\section{Acknowledgements}

The research leading to these results has received funding from the Research for the Benefit of SMEs programme of the European Union's Seventh Framework Programme FP7/2007-2013/ under REA grant agreement number [605086]. 